\title{
Coupled hydro-mechanical modelling of a 1995 Hong Kong landslide
}

\author{
Sabatino Cuomo ${ }^{1, *}$, Angela Di Perna ${ }^{1}$, and Mario Martinelli ${ }^{2}$ \\ ${ }^{1}$ University of Salerno, Department of Civil Engineering, Italy \\ ${ }^{2}$ Deltares, Delft, the Netherlands
}

\begin{abstract}
The paper deals with the modelling of the instability mechanism induced by rainfall in an unsaturated cut-slope. A large-sized landslide occurred in 1995 in Hong Kong (the so-called "Fei Tsui Road landslide"). It was here analysed because it was characterized by unusual dimensions and very large runout distance for the study area. The slope failure was attributed to a decrease in soil shear strength due to the rise of a perched water table above a weak kaolin-rich layer, together with the loss of suction caused by water infiltration during a heavy rainfall event. The hydro-mechanical coupled analyses made through the commercial software Plaxis 2D aimed to investigate the relations between the hydrological variables (i.e., rainfall infiltration, suction, saturation) and the slope response in terms of changes in soil resistance and soil plastic deformations. The study demonstrates that the evaluation of the hydro-mechanical coupling effects on the hydraulic slope response as well as on the stability of the whole slope is a crucial issue to well capture the mechanical behaviour of the unsaturated cut-slope. Different failure scenarios have been also considered in order to match the field observations and to back-analyse the initial condition of the slope before landslide.
\end{abstract}

\section{Introduction}

Slope stability analysis of unsaturated steep cut-slopes is a relevant topic since such slopes remain stable for a long time and then can fail during heavy precipitation.

Soil unsaturated condition is in fact a key factor in both pre-failure and failure stages of a landslide. Before failure, the additional strength related to matric suction is fundamental for the equilibrium of granular soil slopes steeper than the effective friction angle. During the failure stage of rainfall-induced landslides, rain infiltration gradually reduces the soil suction due and consequently the shear strength of soil, up to causing slope failures [1].

Modelling the seepage of rainfall in unsaturated slopes is always a difficult task because infiltration is controlled by many factors, among which suction, permeability and water content of the soil. Moreover, the intensity of antecedent rainfall (i.e. the rain that falls in the days/weeks immediately preceding a landslide event) can affect the stability of the slopes [2].

An interesting case study is presented in this paper, in order to investigate the effects of suction and water infiltration in the failure mechanism of a steep cut-slope. The landslide here analysed is the so-called Fei Tsui Road Landslide, occurred in Hong Kong on 13 August 1995. It was cut-slope failure, unusual both in terms of size and large extent of the debris, which occurred following a period of exceptional prolonged rainfall.

Most of the studies about the Fei Tsui Road landslide have focused so far on the propagation stage of the landslide considering different numerical approaches, all based on continuum models, such as FEM [3, 4], FDM [5], SPH [6 - 10] and MPM [11, 12].

More limited amount of contributions is available for the analysis of the triggering stage. The first slope stability analysis was conducted by Knill (1996) [13] in order to facilitate the diagnosis of both the mechanism and the causes of the landslide. The results of the analyses were achieved without considering the unsaturated characteristic of the materials and showed that the angle of shear strength at failure $\left(\varphi^{\prime}\right)$ for the altered tuff layer was likely in the range $26.5^{\circ} \div 31.5^{\circ}$, associated to a perched water table from $1 \mathrm{~m}$ up to $4 \mathrm{~m}$ above the layer contact.

More recent analyses of the triggering mechanism were conducted by means of limit equilibrium method [11], considering a transient analysis in unsaturated conditions for modelling the rise of the perched water table during the heavy rainfall some hours before the landslide triggering. The authors found that the most probable value of suction was about $51 \mathrm{kPa}$ before rainfall began.

In the following sections, the case study is presented first, and later the methods and data used for modelling.

\section{Case study}

The landslide occurred in the Chai Wan District of Hong Kong as a consequence of the heavy rain fallen between

*Corresponding author: scuomo@unisa.it 
12 and 13 August 1995, when $374 \mathrm{~mm}$ were recorded with a maximum intensity of $60 \mathrm{~mm}$ per hour (Fig. 1).

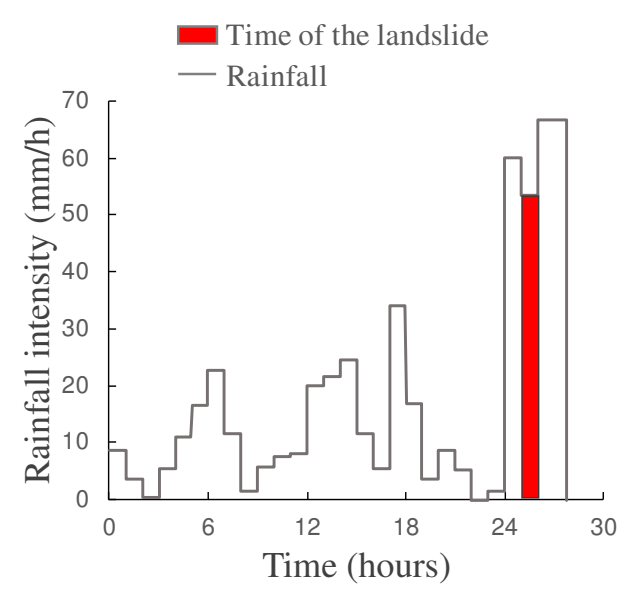

Fig. 1. Hourly rainfall intensity before and at the moment of the landslide.

A deep translational failure took place along a weak and widespread kaolinite-rich layer, due to the formation of a perched water table. The technical investigation of the landslide carried out by the Geotechnical Engineering Office (GEO) of Hong Kong, as stated by the report No. 188 [13], indicated that the perched water level was probably in the range of $1 \mathrm{~m}$ to $4 \mathrm{~m}$ above the clay layer.

The configuration before landslide was represented by a densely vegetated cut-slope with a maximum height of $27 \mathrm{~m}$ and an overall inclination of $60^{\circ}$ towards the North (Fig. 2). The lower part of the slope (up to $8 \mathrm{~m}$ in height from the ground) was constituted by exposed rock, grading from fresh to slightly decomposed volcanic rock. Above this material, there were the kaolinite-rich layer $(0.6 \mathrm{~m}$ in thickness) and the moderately to completely decomposed tuff (Fig. 2).

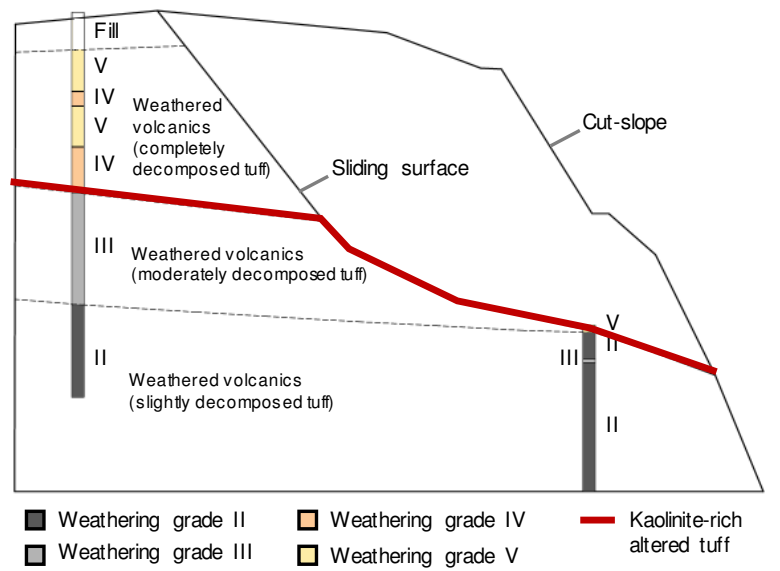

Fig. 2. Geological cross-section of the cut-slope and sliding surface position (modified from Kirk et al. 1997 [14]).

The landslide took place in two stages: the first failure occurred at about 00:55 on 13 August 1995 at the eastern part of the slope, involving some tens of cubic meters. The second stage followed about 20 minutes later and included the large failure, when about 14,000 $\mathrm{m} 3$ of weathered volcanic rock began to move. Debris travelled up to $70 \mathrm{~m}$, covering the whole Fei Tsui Road, which is beneath the cut-slope, entered a playground and even accumulated against a corner of the Baptist Church to a height of about 6 meters. The maximum width and the average depth of the debris deposit were $90 \mathrm{~m}$ and 15 $\mathrm{m}$, respectively (Fig. 3).

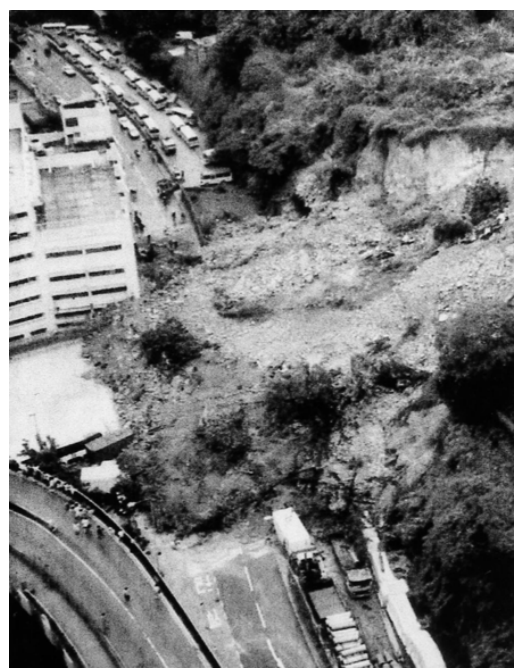

Fig. 3. Landslide debris on 13 August 1995.

The sliding surface of the landslide followed the kaolinitic layer only in the lower part, whereas in the upper part the layer developed above this surface, reaching the highest part of the slope, as shown in Fig. 2. From the field evidence, the lowest zone of the cut-slope (composed by moderately to slightly decomposed tuff) did not form part of the landslide.

About the geotechnical properties of the materials involved into the landslide, several laboratory tests were conducted on soil samples, such as particle size distribution, Atterberg limits, oedometer, triaxial compression and direct shear tests.

The geotechnical features of the soils were taken from the GEO report $n^{\circ} 188$ [13] and they are all specified in Table 1.

Table 1. Geotechnical properties of landslide materials.

\begin{tabular}{|c|c|c|}
\hline Type of soil & $\begin{array}{c}\text { Weathered } \\
\text { volcanic rock }\end{array}$ & $\begin{array}{c}\text { Altered tuff } \\
\text { with kaolinite } \\
\text { veins }\end{array}$ \\
\hline Unit weight $(\boldsymbol{\gamma})$ & $19 \mathrm{kN} / \mathrm{m}^{3}$ & $19 \mathrm{kN} / \mathrm{m}^{3}$ \\
\hline $\begin{array}{c}\text { Average fines } \\
\text { (clay and silt) }\end{array}$ & $71 \%$ & $92 \%$ \\
\hline $\begin{array}{c}\text { Plasticity index } \\
(\text { PI) }\end{array}$ & - & $9 \div 18$ \\
\hline Liquid limit (w $\left.\mathbf{w}_{\mathbf{L}}\right)$ & - & $29 \div 50$ \\
\hline Cohesion $\left(\mathbf{c}^{\prime}\right)$ & $0 \div 10 \mathrm{kPa}$ & $0 \mathrm{kPa}$ \\
\hline $\begin{array}{c}\text { Internal friction } \\
\text { angle }\left(\boldsymbol{\varphi}^{\prime}\right)\end{array}$ & $35^{\circ}$ & $22^{\circ} \div 29^{\circ}$ \\
\hline $\begin{array}{c}\text { Consolidation } \\
\text { coefficient }\left(\mathbf{c}_{\mathbf{v}}\right)\end{array}$ & - & $28 \div 172$ \\
$\mathrm{~m}^{2} / \mathrm{year}$ \\
\hline
\end{tabular}




\section{Materials and methods}

2D finite element analysis was carried out using the commercial code Plaxis 2D, assuming plane strain conditions. The mesh showed in Fig. 4 was made by 15node triangular elements with a maximum and minimum size of $1.864 \mathrm{~m}$ and $0.155 \mathrm{~m}$, respectively. The updated mesh algorithm implemented in the PLAXIS code was used, which is based on the Updated Lagrangian formulation of McMeeking \& Rice (1975) [15].

The materials included in the analysis are the wheatear volcanic rock (Material 1) and the kaolinitic layer (Material 2), both characterized by the same characteristic curves (Fig. 5). The latter were derived from previous analyses made with limit equilibrium methods [11], in which the Van Genuchten model (1980) [16] was used referring to the soil geotechnical parameters of completely decomposed tuff (CDT) proposed in $\mathrm{Ng}$ et al. (2011) [17]. The materials were supposed linear-elastic perfectly-plastic and a nonassociative Mohr Coulomb constitutive model was adopted. For stress states within the yield surface, the behavior is elastic and obeys Hooke's law for isotropic linear elasticity. Hence, both plasticity (i.e. c', $\varphi^{\prime}$ and $\psi$ ) and elastic parameters (Young's modulus $E$ and Poisson's ratio $v$ ) are required as input (see Table1).

The constitutive equation is written in incremental form, in which the effective stress increment $\dot{\sigma}^{\prime}$ is related to the strain increment $\dot{\varepsilon}$ through the stiffness matrix $\underline{\mathbf{M}}$ :

$$
\dot{\sigma}^{\prime}=\underline{\mathbf{M}} \dot{\varepsilon}
$$

The governing equations of consolidation used in Plaxis code follow Biot's theory [18]. Darcy's law for fluid flow and elastic behavior of the soil skeleton are also assumed. According to Terzaghi's principle, stresses are divided into effective stresses and pore pressures:

$$
\sigma=\sigma^{\prime}+\underline{\mathbf{I}}\left(p_{\text {active }}\right)
$$

The vector I contains unity terms for normal stress components and zero terms for the shear stress components. The active pore pressure $p_{\text {active }}$ is given by the expression:

$$
p_{\text {active }}=\alpha_{\text {Biot }} S_{\text {eff }} p_{w}
$$

where $\alpha_{\text {Biot }}$ is Biot's pore pressure coefficient and $S_{\text {eff }}$ is the effective degree of saturation $S_{\text {eff }}=\frac{S-S_{\text {res }}}{S_{\text {sat }}-S_{\text {res }}}$ with $S_{\text {res }}$ representing the residual saturation and $S_{\text {sat }}$ is the saturation degree for saturated condition, so it is equal to 1 . Considering incompressible grains, Biot's coefficient is equal to unity.

The pore water pressure $p_{w}$ can be divided into two components:

$$
p_{w}=p_{\text {steady }}+p_{\text {excess }}
$$

Steady-state pore pressures $p_{\text {steady }}$ is an input data, since it is generated from the initial piezometric line. Excess pore pressures $p_{\text {excess }}$ are evaluated during plastic calculations or during a consolidation analysis.

The incremental form of the Hooke's law can be inverted in order to obtain the elastic deformations:

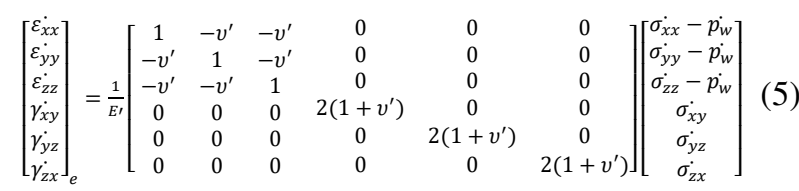

The increment of pore water pressure coincides with the increment of excess pore pressure:

$$
p_{w}=p_{\text {excess }}=\frac{\alpha_{\text {Biot }} \dot{\varepsilon}_{v}}{n C_{w}+\left(\alpha_{\text {Biot }}-n\right) C_{s}}
$$

where $n$ is the soil porosity, $C_{w}=\frac{1}{K_{w}} \quad$ is the compressibility of the water and $K_{W}$ is the bulk modulus of the water, $C_{S}=\frac{1}{K_{S}}$ is the compressibility of the solid material and $K_{S}$ is the bulk modulus of the solid material.

The water bulk modulus changes in partially saturated condition:

$$
K_{w}^{u n s a t}=\frac{K_{w}}{1+\frac{K_{w}}{S_{w}}\left(-\frac{\partial S_{w}}{\partial p_{w}}\right)}
$$

in which $\partial S_{w} / \partial p_{w}$ is the slope of the water retention curve shown in Fig. 5. Pore water pressure is not an internal variable of the constitutive model, and the strength parameters are not modified by any change in pore water pressure. The latter anyway changes the soil stress in the landslide.

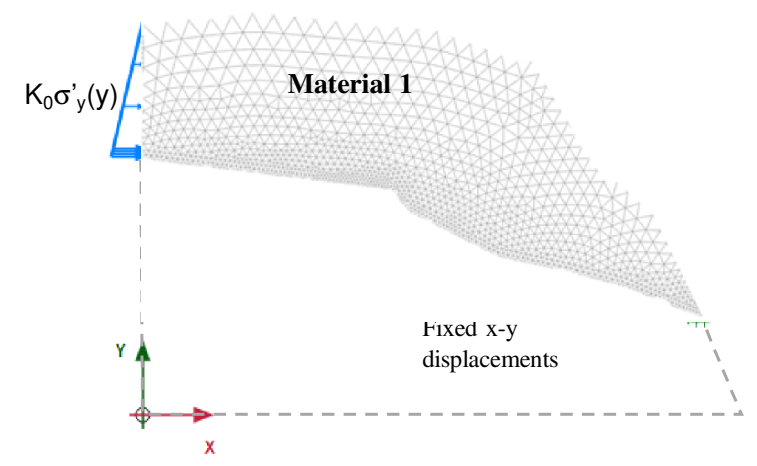

Fig. 4. Input geometry and computational mesh. 


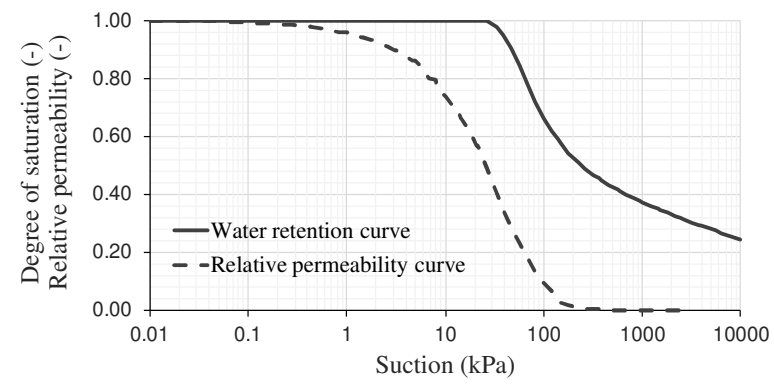

Fig. 5. Soils characteristics curves employed in the analysis.

Table 2. Input parameters used in the analysis.

\begin{tabular}{|c|c|c|}
\hline Type of soil & Material 1 & Material 2 \\
\hline Unit weight $(\boldsymbol{\gamma})$ & $19 \mathrm{kN} / \mathrm{m}^{3}$ & $19 \mathrm{kN} / \mathrm{m}^{3}$ \\
\hline $\begin{array}{c}\text { Saturated hydraulic } \\
\text { conductivity }\left(\mathbf{k}_{\text {sat }}\right)\end{array}$ & $5 \cdot 10^{-5} \mathrm{~m} / \mathrm{s}$ & $10^{-7} \mathrm{~m} / \mathrm{s}$ \\
\hline Cohesion $\left(\mathbf{c}^{\prime}\right)$ & $5 \mathrm{kPa}$ & $0 \mathrm{kPa}$ \\
\hline $\begin{array}{c}\text { Internal friction } \\
\text { angle }\left(\boldsymbol{\varphi}^{\prime}\right)\end{array}$ & $35^{\circ}$ & $29^{\circ}$ \\
\hline Dilatancy angle $(\boldsymbol{\psi})$ & $0^{\circ}$ & $0^{\circ}$ \\
\hline Young modulus $\left(\mathbf{E}^{\prime}\right)$ & $10000 \mathrm{kPa}$ & $10000 \mathrm{kPa}$ \\
\hline Poisson ratio $(\mathbf{v})$ & 0.35 & 0.35 \\
\hline
\end{tabular}

The materials parameters used as input in the analysis are shown in Table 2.

After an initial equilibrium phase of geostatic stress, a fully-coupled flow-deformation analysis was carried out in order to simulate the decrease in soil suction and the rise of the perched water table during the heavy rainfall before the landslide triggering. Three different cases with different initial suction values (40, 50 and 60 $\mathrm{kPa}$ ) were taken into account here in order to show the influence of suction in the triggering of the landslide.

The initial suction priori to rainfall was set as a uniform vertical distribution within the whole computational domain for the sake of simplicity.

\section{Numerical results}

A selection of the obtained results is shown in this section. In particular, the distributions of the plastic points and the displacements trends over time were taken into account for the different initial suction cases. The comparison of the results represented in Figs. 6, 7 and 8 highlights that for the lowest suction value $(40 \mathrm{kPa})$ the yielded zones are more widespread than for the other cases $(50$ and $60 \mathrm{kPa}$ ). In the latter cases, the plastic points mostly appear just before the failure time. From that comparison it is evident that increasing the initial suction corresponds to an overall decreasing of the yielded areas.

Another interesting outcome is linked to the failure mechanism. In fact, all the three cases show that the plastic zones first appear within the kaolinitic layer. Then, the plastic zones extend upward along this layer and in the proximity of the foot of the slope. This mechanism suggests that the slope was probably affected by a retrogressive failure.

The results in Fig. 9 show the temporal trend of displacements in the three cases. A first observation can be made with reference to the time of failure, reached when the displacements show a sudden increase.

In fact, for the lowest initial suction the failure time is about half of that observed, while an initial suction of $50 \mathrm{kPa}$ leads to a failure time very close to that reported by the eyewitnesses. This value is similar to that estimated by Cuomo et al. (2019) [11] through limit equilibrium analyses as the most probable value of suction at the start of the rainstorm reported in Fig.1.

In accordance to the plastic zones, the time trend of displacements in all the cases shows that the failure begins from the lowest part of the slope (point B). In fact, moving away from point $\mathrm{B}$, the displacements are smaller or negligible (points D and E).

The results even show that the initial suction has effect on the displacement rate reached inside the slope at failure. In fact, for the case of $40 \mathrm{kPa}$ the displacement rate remains quite constant over time, in contrast to the other cases, when the slope reached the failure fairly fast. For the highest value of suction $(60 \mathrm{kPa})$ the displacement rate is about zero for the most part of the pre-failure stage and abruptly increases during the failure stage. For the most probable value of suction $(50 \mathrm{kPa})$, the displacements trend seems to be a combination of the above two cases, since in most of the analysis the increment is quite constant and only at failure suddenly increases.
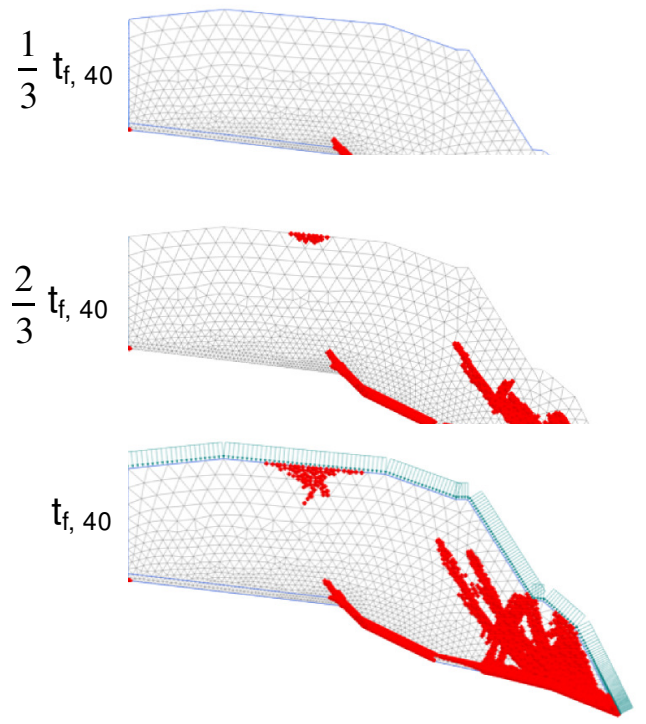

Fig. 6. Distribution of plastic points for initial suction of $40 \mathrm{kPa}\left(\mathrm{t}_{\mathrm{f}, 40}=12.8\right.$ hours $)$. 


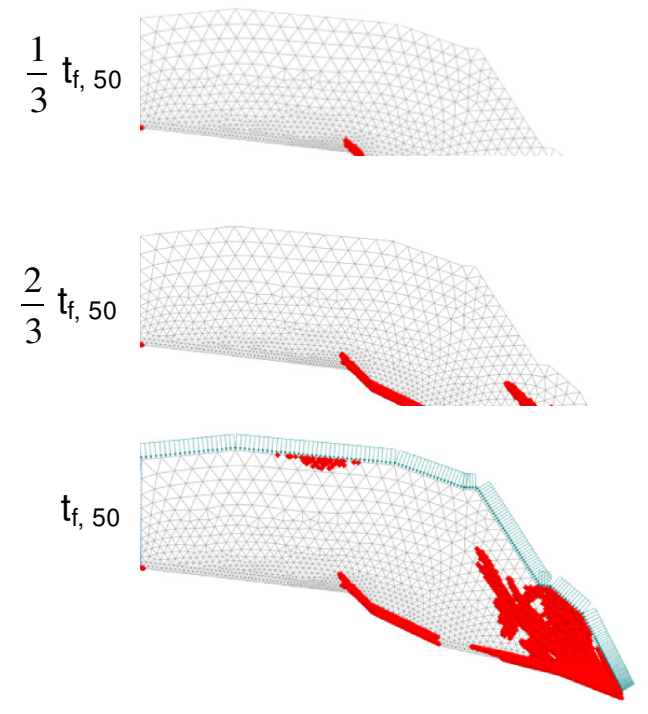

Fig. 7. Distribution of plastic points for initial suction of 50 $\mathrm{kPa}\left(\mathrm{t}_{\mathrm{f}, 50}=24.7\right.$ hours $)$.
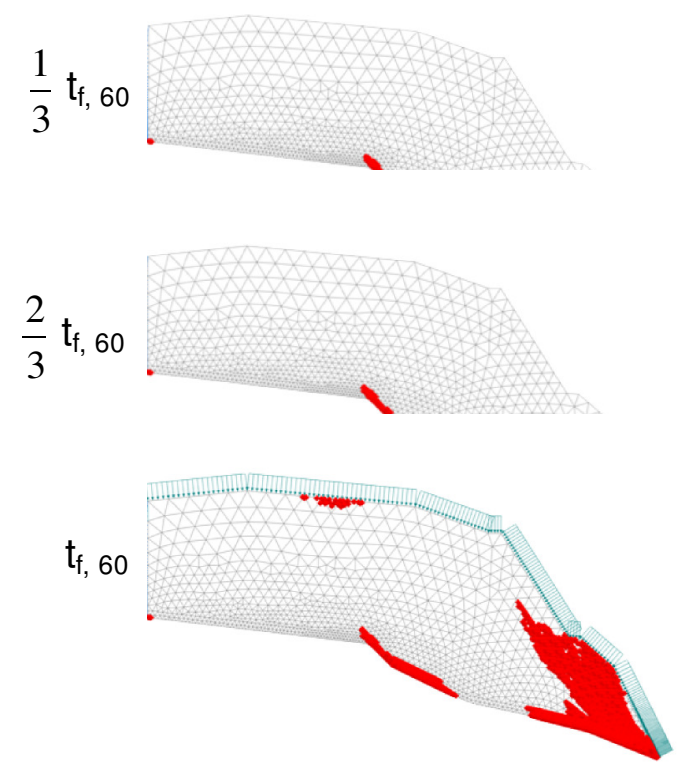

Fig. 8. Distribution of plastic points for initial suction of 60 $\mathrm{kPa}\left(\mathrm{t}_{\mathrm{f}, 60}=27.2\right.$ hours $)$.
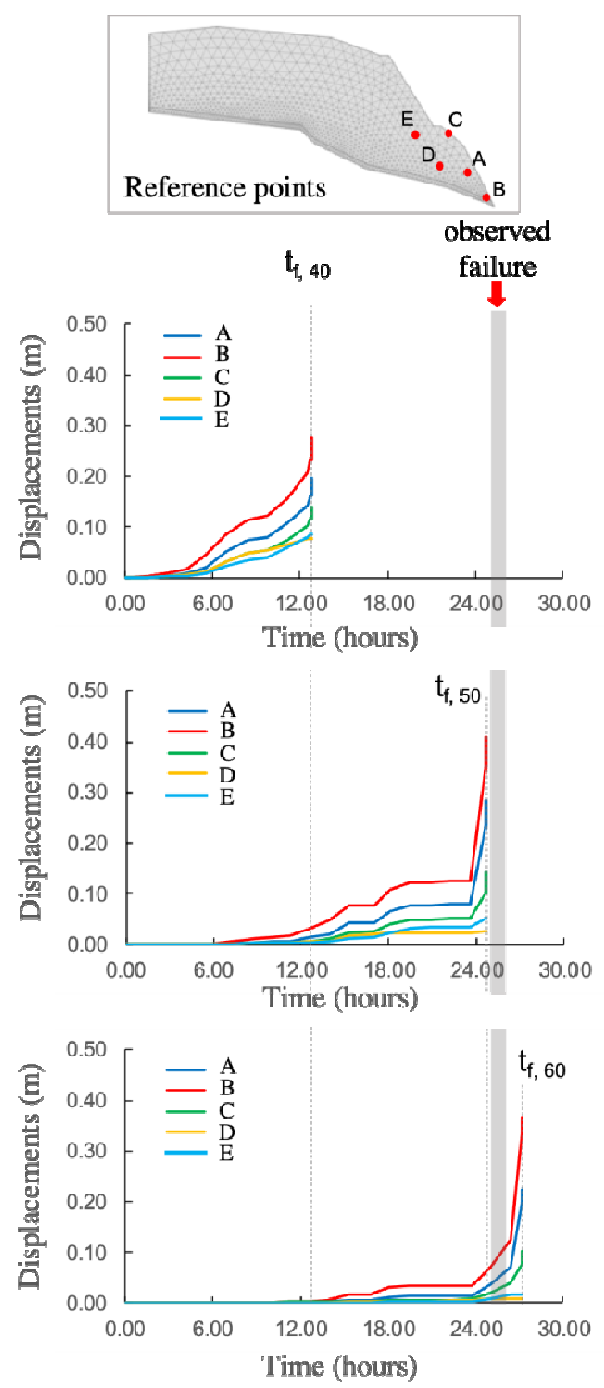

Fig. 9. Trend of displacements over time for the three cases.

\section{Conclusions}

The study provided a new contribution in understanding the triggering mechanism of the Fei Tsui Road landslide. The coupled-hydromechanical modelling of the landslide through finite element method enabled to analyse the simultaneous development of deformations and water pore-pressure even in unsaturated conditions.

In particular, soils characteristic curves of unsaturated soil, transient boundary conditions and initial suction related to the antecedent rainfall were used to capture the role of suction and partially saturated conditions in the failure of a steep cut-slope.

The results demonstrated that the initial suction (i.e. when rainfall begins) leads to different failure scenarios, so it must be carefully considered in the stability analysis of steep slopes. Moreover, the spatial distribution and development patterns of plastic zones with the time trend of displacements gives additional information about the type and evolution of failure, which seems to be retrogressive in the case of Fei Tsui Road landslide.

The most reliable value of initial suction and the unsaturated characteristics of the soils here outlined for the slope could be useful to conduct further analyses in 
order to simulate pre-failure, failure and post-failure stages of the landslide.

\section{References}

1. L. Cascini, S. Cuomo, M. Pastor, G. Sorbino. ASCE's Journal of Geotechnical and Geoenvironmental Engineering, 136(1), 85-98. (2009)

2. A. Rahimi, H. Rahardjo, E.C. Leong. Journal of Geotechnical and Geoenvironmental Engineering, 137(5), 483-491. (2010)

3. H. Chen, C. F. Lee. Canadian Geotechnical Journal, 37(1), 146-160. (2000)

4. R. C. H. Koo, J. S. H.Kwan, C. Lam, G. R. Goodwin, C. E. Choi, C. W. W Ng, W. K. Pun. Canadian Geotechnical Journal, 55(8), 1081-1094. (2017)

5. F. Wang, K. Sassa. Physics and Chemistry of the Earth, Parts A/B/C, 35(3-5), 149-161. (2010)

6. M. E. Sanchez, M. Pastor, M. G. Romana. Georisk: Assessment and Management of Risk for Engineered Systems and Geohazards, 7(4), 250-266. (2013)

7. M. Pastor, T. Blanc, B. Haddad, S. Petrone, M. S. Morles, V. Drempetic, S. Cuomo. Landslides, 11(5), 793-812. (2014)

8. S. Cuomo, M. Calvello, V. Villari. In Engineering Geology for Society and Territory-Volume 2 (pp. 1635-1639). Springer, Cham. (2015)

9. S. Cuomo, M. Calvello, P. Ghasemi. In Workshop on World Landslide Forum (pp. 513-521). Springer, Cham. (2017)

10. M. Calvello, S. Cuomo, P. Ghasemi. Computers and Geotechnics, 92, 11-21. (2017)

11. S. Cuomo, A. Di Perna, P. Ghasemi, M. Martinelli, M. Calvello. (2019).

12. W. L. Lee, M. Martinelli, C. L. Shiehi. In Proceedings of the XVII ECSMGE-2019 (pp. 1-8) (2019)

13. S.J. Knill . GEO REPORT No. 188, Hong Kong. (1996)

14. P. A. Kirk, S. D. G. Campbell, C. J. N. Fletcher, R. J. Merriman. Journal of the Geological Society, 154(6), 1009-1019. (1997)

15. R. M. McMeeking, and J. R. Rice. International Journal of Solids and Structures, 11(5), 601-616 (1975).

16. Van M. Genuchten. Soil Sci. Soc. Am. J. 44, No. 4, 892-898. (1980)

17. C. W. W. Ng, H. N. Wong, Y. M. Tse, J. W. Pappin, H. W. Sun, S. W. Millis, A. K. Leung. Géotechnique, 61(6), 511. (2011)

18. M. A. Biot. The Journal of the acoustical Society of America, 28(2), 179-191. (1956) 